\title{
Developing primary care services for young people
}

\author{
Linda Hughes, Senior Health Promotion Officer \\ Correspondence: Linda Hughes, Health Promotion Service, The Kernow Building, Wilson Way, Pool, Redruth, Cornwall, TR15 \\ 3QE, UK. Tel: 01209313419 Fax: 01209314491
}

(Accepted April $\left.3^{\text {rd }}, 2000\right)$

\begin{abstract}
Summary
The Cornwall and Isles of Scilly Health Promotion Service and Cornwall Youth Service have been working in partnership to facilitate the planning and promotion of high quality attractive and relevant designated health services for young people. This partnership arose from a joint project in North Cornwall looking at unwanted teenage pregnancies. It involved research with young people about their perspective of health services in their area, and a theatre in education project with the Barbican Theatre working with primary health care teams to raise awareness about the issues relating to health care for young people. The team have presented their work at several conferences, it has won a NHS 50 National Award sponsored by GlaxoWellcome, and has attracted much interest locally and nationally from policy makers and practitioners. This paper describes how the team came together, the various stages in the development and execution of the project, the outcomes and recommendations
\end{abstract}

\section{Key words}

accessibility, barriers, confidence, listening, partnership, primary care, trust, young people' services

\section{Key message points}

- The aim of this initiative is to establish easy access to a range of essential services for young people.

- Such services need to be delivered in an environment that meets the expressed needs of young people.

To ensure accessibility it is important to address the physical, psychological and social structures in place at present which inhibit young people from use of services.

- Services need to have consistent and clear policies on confidentiality and the treatment of young people.

\section{Our Vision}

To create a healthy young Cornwall by working in partnership with young people to build a range of excellent health services, which support healthy living.

\section{Background}

In 1997 Cornwall Youth Service was successful in obtaining funding from the Cornwall and Isles of Scilly Health Authority to set up a research project to address high levels of unplanned teenage pregnancy in a part of North Cornwall.

Prior to this time in 1996 a multi-agency group, the Adolescent Health Alliance, was set up by the Health Promotion Service. It was from the Alliance that a team was formed to work collaboratively, at first addressing unplanned teenage pregnancy, and now to provide better access to holistic health care. The process in which the team has been engaged has been complex with many strands. A description of the process and the strands of work follows.

\section{The Adolescent Health Alliance}

In 1996 The Cornwall and Isles of Scilly Adolescent Health Alliance was formed. This is a multi-agency group, which formed originally to work co-operatively and collaboratively to address adolescent health issues. Initially sexual health was the main focus. The systems in place at that time in many ways did not encourage partnership working, as agencies were competing for their own survival and funding. The objectives of this Alliance were:

- To work towards meeting the Health of the Nation targets.

- To address rural problems with respect to isolation and reaching services.

- To identify existing services and to determine how to improve their use.

- To identify barriers to use of services.

- To listen to young people. (N.B. In 1996 'To listen to young people' was the last objective on the list.)

In 1997, when the County Youth Service received funding to address unplanned teenage pregnancy in North Cornwall, a Youth Worker, a Health Promotion Officer and a General Practitioner (GP), all members of the Adolescence Health Alliance, formed a team to work collaboratively on the project.

These three members of the team all had significant experience in setting up young people's services. A team of actors from the Barbican Theatre, Plymouth who are experienced in theatre in education, were recruited to work with the team, and a Researcher was recruited by the Youth Service.

The project, which was developed in two overlapping stages, needed a name. Our choice was: Listening to Young People.

\section{Aim}

The Listening to Young People project aimed to reduce the levels of teenage pregnancy in the project area by making existing primary care services more accessible to the 13-19 year old age group.

\section{Objectives}

The project had the following objectives:

- To look at existing services.

- To find out from young people how accessible the services were.

- To consult young people about what services they feel would be the most suitable, and how these could be promoted.

- To look at existing provision for young parents and set up support groups where appropriate.

- To look at what training and support could be offered to parents of the client group to enable them to deal more effectively with sexuality issues with teenagers.

- To work with young people to produce a computer information disk about sexual health and services available in the locality.

\section{Stage one: Research}

June 1997-February 1998 involved a Researcher working with focus groups of young people in the age range $13-19$ 
years, to examine their perceptions of existing services, to listen to and record their experiences, and to look at what provision they would find most acceptable. The study was carried out in the Bodmin/Wadebridge area of North Cornwall.

Single sex focus groups were interviewed by a Youth Worker, and the participants were invited to fill in a questionnaire at the end of each session. Access to the young people was provided in a variety of settings, including schools and youth groups.

The primary method of data collection was through a structured, themed group interview, conducted in an informal manner, where the interview was recorded. The interviewer made field notes to amplify and clarify the issues raised in the discussion. The ground rules for the focus groups emphasised the confidentiality of the exchanges and the sensitivity of the issues under discussion.

The interview schedule was divided into sections to include a preamble, an icebreaker raising the topic of information about sex, and a discussion of the dilemmas of using local services.

\section{Stage two - Training for primary care teams in health centres}

The project team wrote to every practice in the Bodmin/Wadebridge target area $(n=5)$, offering a free training session to raise awareness about the issues facing young people when trying to access sexual advice.

\section{Responses}

There was one prompt response; this was from a practice already receptive to issues and wishing to effect change. Three responses were received after a follow-up letter and telephone call. One practice did not respond at all to the offer of training.

The team recognised the following difficulties in accessing the training session:

- Lack of time

- Assessing priorities; young people form a small percentage of practice clientele. Primary health care teams have a duty of care to all their patients and not exclusively to our client group.

(Could it be that doctors are more illness and disease orientated rather than providing services for the well?)

\section{The training package}

The training package included the following:

- An initial visit to the practice was made by the Youth Worker, the Researcher and the Health Promotion Officer to present the aims and objectives of the project.

- This was followed by a training session facilitated by the GP project partner using participative theatre in education to raise awareness and facilitate change.

- A follow-up session by the Health Promotion Officer to discuss issues raised during the training, and to identify areas where change could be negotiated.

Ongoing support was offered by the project team for agreed planned interventions including:

- Policy clarification.

- Implementing new strategies.

- Provision of information.

- 'Bridge building' activities between young people and the practice.

\section{Training format}

- Introductions. Members of the project team introduced themselves and explained their professional background and experience with young people.

- A warm-up session was conducted to enable an exchange of information between the staff teams and project team. By keeping this part of the session light hearted it also gave an opportunity for fun and relaxation.

- Explanation of the training process by the GP facilitator. Up to this point a full explanation of the training process had not been given, as it was felt that prior knowledge would jeopardise the effectiveness of the programme.

The project team needed a true picture of policy, systems, attitudes and knowledge within the practice. It was useful to observe communication, teamwork and consistency of approach. It was important to get a true picture of how the practice worked, and not a show put on for our benefit, if we were to measure change effectively.

The GP facilitator explained to the staff team that in order to educate young people to take responsibility around sexual health issues, it was essential to also educate health professionals. For example, a leaflet that promises that young people can talk to their doctor in confidence may be misleading if the practice does not have a clear policy. The facilitator also reassured the staff that the process was not a role-play but an opportunity for volunteers to participate in their usual professional role. The action could be stopped at any time if the participants felt uncomfortable or out of their depth.

The Health Promotion Officer took the role of observer and made notes during the training process.

The training offered a unique opportunity for the practice to examine the services they are offering and to test systems already in place. They were reassured that there would be no personal criticism.

The training was designed to give a clear idea of the whole service from first point of contact by the young person.

Professional actors, experienced in interactive theatre, took the role of two young people as they journeyed through the primary health care setting. At each stage they encountered health professionals who had volunteered to re-enact their own roles, i.e. receptionists playing receptionists, GPs playing GPs, etc. These interactions were observed by each member of the primary health care team (a potentially threatening situation as staff may feel that they are on show). Individuals were frequently reminded that if they felt uncomfortable the action could be halted and the difficulties discussed.

At relevant points in the process the action was frozen to discuss and analyse whether what was happening was a true representation of what occurs on a day to day basis and, if so, whether improvements could be made. In this way the health centre as a place of work and as a health provider was analysed from 'the inside'.

In asking staff to view the issues emotionally as well as intellectually a discussion of judgements and values was allowed to take place; a process which tends not to occur during clinical training sessions. This training structure created a framework within which there was an opportunity to negotiate and initiate change.

At the end of the session staff were asked to fill in a feedback form. 


\section{Post-training follow-up session}

Again, this presented problems in terms of negotiating time with the practices, particularly as we were keen to hear the views and ideas of as many participants as possible. It was very important to hear the views of receptionists, as they are in the front line of patient contact and act as a bridge between patients and health professionals.

The project team asked for a 1-hour follow-up session, this being an opportunity to receive feedback, observations and suggestions from the staff perspective, whatever their role in the team.

Members of the project team then fed back their own observations, perceptions and suggestions with a view to encouraging debate. Criticism of the process that would assist us in our work and give additional insights was invited.

A pack of information was provided to each participating practice.

\section{Common issues raised}

- Internal environment.

- Lack of information friendly to young people and relevant to their presenting issues.

- Unclear policy relating to confidentiality, particularly for under $16 \mathrm{~s}$.

- Information given during consultations, particularly relating to unplanned pregnancy, did not always present the patient with a full range of options.

- Mistrust of young people's motives in visiting the practice.

- Personal attitudes and values.

- Confusion about the legal position as it related to confidentiality with under $16 \mathrm{~s}$, the Children Act, child protection procedures and the Fraser Guidelines.

- Misinformation.

- Accessibility: i.e. How much flexibility was there around appointments, for example for a young woman seeking emergency contraception who had to catch a school bus.

- Time pressure on all staff, which could get in the way of empathic response.

\section{Training outcomes evaluation \\ Written evaluation}

In a rehearsal session, which was undertaken out of the County, we measured staff perceptions of quality and relevance of the training, and asked for suggestions for improvement of the process. We also asked participants what they felt they took away from the session. As a result of this feedback the process was 'finely tuned' prior to presenting this to the target practices. Having received their comments we realised that we needed to gather more information to enable us to look more clearly at the process and its effects.

We identified the following as useful information:

- Professional role (different perspectives).

- Individual recognition of need for change or improvement.

- Whether the practice displayed a confidentiality policy.

- Did the practice have an agreed policy on confidentiality and treatment of young people? If not, would they be prepared to produce one? Also, would they like assistance in producing one?

- Whether the practice displayed a leaflet for young people explaining what was on offer.

- Had they identified any training needs for themselves?
- Had they identified any training needs for the practice?

- Were they willing to allow us the opportunity of working with them to effect change? (By asking this last question we wanted to demonstrate our commitment to supporting them through change, but only if this was acceptable to them.)

A final question asked whether they had received any training in sexual history taking, and was asked purely to gather information for planning training. Was it reasonable to expect a high level of skill and sensitivity in consultations relating to sexuality if staff had not received even basic training? (For example, in taking a sexual history?)

We also invited further comments, which may help in the planning of future interventions, training or support.

\section{Process evaluation}

1. Individuals' recognition of need for change within the practice setting.

2. Areas for change identified.

\section{Outcomes}

Research undertaken by the project has demonstrated the following outcomes:

- The fostering of a sense of team, and the empowerment of those traditionally at the bottom of the hierarchy in the primary healthcare setting (i.e. reception staff) who play a key role in being the front line of communication.

- An interactive learning structure which creates a framework where there is an opportunity to negotiate change.

- An opportunity for primary healthcare teams to examine the service they offer young people and, because the whole team is involved, to obtain a clear idea of the whole service from the first point of contact.

- The fears, perceptions and barriers to existing sexual health services identified by young people at the beginning of the project have been shown to be justified and real through the subsequent work with primary healthcare teams.

- Every practice recognised the need for some changes to be made.

Based on the findings, the question has been raised 'to what extent are clinical judgements about young people's health related to individual moral viewpoints and, therefore, sometimes limiting choices for patients?'

\section{Conclusion}

Much research has been carried out to identify young people's perceptions and needs in the area of sexual health. Our own small project has corresponded well with national findings which suggest that young people's fears around confidentiality are the major barrier to accessing information and advice through doctor's surgeries. Fears of being seen by a friend or relative and inconvenient opening times are secondary, but very important factors. Young people's fears are well founded.

'Listening to young people' is now at the top of the team's agenda.

\section{Theatre in education for primary care teams}

The training package was very successful in that it has been a catalyst which has enabled change to be negotiated. Health promotion initiatives funding was made available, which enabled the training to be offered to primary care 
teams in practices throughout Cornwall. So far the team has worked in 17 healthcare settings, with more planned.

\section{Conferences in Cornwall, London and Cheltenham.}

The team has presented its work at conferences in London (Society for the Advancement of Sexual Health), Cornwall (The Adolescent Health Alliance) and in Cheltenham (Faculty of Family Planning on Clinical Effectiveness, September 1999). Since then, the team has been invited to provide training in Instow in Devon, Street in Somerset, and have had other invitations to provide training throughout the country, which cannot be met.

A presentation was made at a Cornwall Child Protection conference in April 2000 and the team agreed to provide training in Edinburgh and Croydon in May 2000. Other negotiations are underway to examine how the team can meet other training requests.

A snapshot of the training was included in the Team's presentation at the Faculty of Family Planning Conference on Clinical Effectiveness in September 1999. It has won a NHS 50 National Award sponsored by Glaxo-Wellcome and has attracted much interest locally and nationally from policy makers and practitioners.

\section{Designated services for young people}

Partnership between the Youth Service and Health Promotion Service remains at the heart of the ongoing development of this initiative.

\section{Testing the water}

It was clear that the theatre in education training package had served as an effective tool in raising awareness, facilitating recognition of the need for improvement and change in service provision. It is, however, not easy to provide a user-friendly service for young people in a health centre which aims to meet the needs of adults too. The GP partner joined the Health Promotion Service from November 1998 - March 1999 on a part-time basis to consult with others and test the idea of a more holistic designated health service for young people. This would need multi-agency support and would need to be informed by the expressed need of young people. During this 6-month period of consultation it became clear there is widespread support for a designated health service for young people. At a strategic level, the County Children's Interagency Steering Group supports this initiative.

Cornwall is now a Health Action Zone (HAZ), and HAZ funding was obtained through a HAZ Fellowship. With this, the GP was seconded for 6 months on a full time basis to the Health Promotion Service to work with the Youth Service and Health Promotion Service Team to further develop the initiative (Strategic Partnerships).

\section{Components of the partnership}

To date the Health Promotion/Youth Service partnership has two main components:

\section{Consultation with young people}

Cornwall Youth Service is working to establish consultation with young people themselves to ensure that the initiative is informed and led by them (Partnership with young people).

- A new post of Youth Participation Link Worker is funded from $1^{\text {st }}$ April 2000 for 2 years. This post will enable the ongoing consultation with young people to continue.
- The Youth Service have conducted a preliminary consultation exercise with young people across the county, particularly talking to those groups who are marginalised, e.g. those excluded from school and those in care of Social Services.

- Work is also taking place with the Drug Action Team and 'Young People Cornwall', which is a voluntary youth agency, to establish regular forums of young people. Young People Cornwall has started this process by holding the first of a series of conferences planned throughout the County to allow the partnership to explain to young people the vision of Designated Health Services and to ask them how it can best be achieved.

\section{Consultation with other organisations}

Discussion and consultation has taken place with a range of statutory and voluntary organisations working within the county to gain support for the concept. We now have broad outline support from the following agencies:

- Cornwall and Isles of Scilly Health Authority

- Social Services

- Local Education Authority

- Cornwall County Council

- Cornwall Brook Advisory Service

- Council for Social Responsibility

- Local Medical Committee

- Child Protection Team

- Child and Family Centre

- Adolescent Health Alliance

- Children's Interagency Steering Group

- National Society for the Prevention of Cruelty to Children

- Promoting Effective Parenting

- Out of School Education Service

- Cornwall Association of Secondary Headteachers

- Relate

- Genito Urinary Service

- Devon and Cornwall Housing Association

- Red Cross

- Young People Cornwall

- Six District Councils

- Primary Care Boards

- Cornwall Alcohol and Drug Agency

- Contraceptive and Sexual Health Service (Family Planning Service)

- Freshfield

- Cornwall Heathcare Trust

- Truro Young Women's Centre

- Pepper Harrow Foundation

- Papyrus

- Children's Society

- Rural Community Development Council

- Department of Primary Care, Plymouth University

- Clinical Effectiveness Unit of Faculty of Family Planning

The involvement of grass roots staff is an important element of the discussion and consultation process, as it is crucial to the success of the initiative ('Locality Partnerships').

\section{Designated health services}

These services will be delivered within appropriate physical surroundings and will reflect cultural understanding of young people's needs. The aim of this initiative is to establish easy access to a range of essential services 
delivered in an environment that meets the expressed needs of young people.

To ensure accessibility, it will be important to address physical, psychological and social structures in place which, at present, inhibit young people from using services. This will involve looking at locations, timing and structures, to address the physical barriers. It will also need to address problems of attitude of staff, issues of confidentiality, 'user friendliness' and disempowerment of young people to overcome some of the psychological and social barriers to accessing services.

There is a clear need for all agencies to understand that involvement in this initiative would mean true collaboration and a willingness to change those structures and protocols within their agencies which act as a barrier to the achievement of the partnership vision.

In order to take this initiative forward, partnerships have now been forged at County and at locality level. These are both strategic and operational.

Input from local young people, both in establishing the 'look' of services in their area and also in the ongoing evolution of services, is an important part of this process.

It is envisaged that young people will develop a sense of ownership and trust, which at present is lacking, This will allow them to take responsibility for their well-being and give them a voice in the long-term planning of future services.

At a strategic level key representatives from the Youth Serving Agencies, Social Services, LEA, Local Authorities, the Voluntary Sector and the NHS, have been brought together with young people to act as a lead body to take responsibility for designing an overall framework for young people's Designated Health Services and agreeing and setting quality assurance criteria. This criteria will become a brand used to quality assure, or 'kite mark' the delivery of services to young people at local level, and will lead to a clear corporate identity. This process will be facilitated by a project team from the Youth Service and Health Promotion Service and informed by the ongoing consultation with young people.

At an operational level partners will be 'contracted' to provide services to support the county-wide development and continuous improvement of Designated Health Services to Young People, i.e. training, publicity and promotion, research and development, monitoring and evaluation, direct health service provision etc. Some are already in existence, for example:

- The 'Children's Health Action Zone One Stop Shop Partnerships' which facilitate operational workers to have an input into the strategic planning of the Children's Health Action Zone.

- The Children's Interagency Steering Group, which oversees the Designated Services for Young People Programme Management Board.

- The Adolescent Health Alliance which enables operational workers throughout Cornwall with a particular interest in young people's health issues to participate and shape the process (sexual health was the original main focus of this group's work) and remains very high on the national and local health agenda.

Having established a service 'brand', operational partnerships at locality level will work with young people to plan and deliver Designated Health Services within the overall quality assured county framework.

It is envisaged that different localities will have different models for service delivery, but that each will work to an agreed basic agenda to ensure that the oft-repeated needs of young people are met.

The project team has facilitated a series of 27 locality consultation meetings to communicate with grass roots staff and forge locality partnerships. This process of bringing people together has acted as a catalyst to encourage cooperative working at locality level.

There is now widespread support for the vision of Designated Health Services for Young People across Cornwall and Isles of Scilly. Apart from the Health Action Zone funding, which enabled the GP to be seconded to the Health Promotion Service for 6 months, other bids for funding have been submitted and the team is optimistic for the future.

\section{The way forward}

There is deliberate reluctance on the part of the team to be proscriptive, as true partnership requires that power and decisions be shared. The recommendations from the preliminary Youth Service Consultation with young people will inform decisions and the ongoing process. These recommendations are given below.

\section{Recommendations}

- Designated Health Services will be created and/or developed, aimed at providing specifically for the unmet needs of young people.

- Young people will be consulted at every stage of the planning process and will be integral to future development.

- Services provision will share a brand identity but will respond to local needs, and may include different methods of delivery and organisation. Existing quality services addressing local need will be included and supported.

- Services will be multi-agency thus making possible a range of quality specialist services. Specialist advice and information provision will seek to address wider health and social issues, such as homelessness and poverty.

- Services will take a broad inclusive definition of health, be holistic and proactive as well as reactive.

- Services will be confidential. Where child protection is an issue young people will be clearly informed of the procedures.

- Services will be well sign-posted. This will involve proactive publicity, reaching out to young people where they meet. Detached youth workers will assist this process.

- Staff will be trained and sensitised to combat the psychosocial barriers that prevent young people accessing or utilising current provision. In particular, recognising the need to demonstrate the commitment to the project ethos, ensuring that clients are respected, listened to and not pre-judged.

- Staff will have a clear understanding of young people's lifestyles and experience, enabling the issues they bring to be understood in their social context.

- Services will be delivered in appropriate physical environments and reflect a cultural understanding of young people's needs. This will include easy accessibility in terms of location and opening times.

The team continues to listen to and work with young people.

The shared values and working relationships within the project team and the working relationships members have 
with staff throughout Cornwall have assisted the process. Trust and partnership are vital ingredients which remain key to the future success of the initiative, and we are privileged to be part of the combined effort to provide the services young people need and deserve.

\section{The Project Team}

The Project Team initially involved in the early development of Designated Services for Young People were:

Mary White, Cornwall County Youth Service

Jon Tilbury, GP Cornwall and Isles of Scilly Health

Promotion Service

Linda Hughes, Senior Health Promotion Officer, Cornwall and Isles of Scilly Health Promotion Service

Sheila Snellgrove, Joint Artistic Director, The Barbican
Theatre Plymouth

Jane Newton-Chance, Associate actor

Richard Ludlow, Cornwall County Youth Service

Sally Lloyd, Cornwall and Isles of Scilly Health Promotion Service

Mary White is no longer involved and Martin Courts (Health Promotion Service) has joined the team. The multiagency Management Board has brought together new team members with ideas and commitment to contribute to realising the Vision.

Statements on funding and competing interests

Funding. The following agencies have contributed: Health Action Zone (HAZ), Quality Protects from Social Services, National Society for the Prevention of Cruelty to Children, Youth Services, Health Promotion Services.

Competing interests. None. 